\title{
アクリル酸グラフト綿布の性質
}

武庫川女子大学家政学部 过和一即・池田房代 長公川智三・中尾時枝

\section{PROPERTIES OF ACRYLIC ACID GRAFTED COTTON FABRICS}

\author{
By Waichiro Tsuji, Fusayo Ikeda, Satomi Hasegawa and Tokie Nakao
}

(Faculty of Home Economics, Mukogawa Women's University, Ikebiraki-cho, Nishinomiya City, Hyogo Prefecture, Japan)

Properties of cotton fabrics grafted with acrylic acid in 6-16\% were examined and compared with carboxymethylated cotton fabrics previously studied. In the case of the grafting by electron beam irradiation, the decrease in the tensile strength of the warp yarns of the grafted fabrics was slight. Moisture regain was somewhat increased by the acrylic acid grafting, although not so much as carboxymethylation. Dyeability for basic and cationic dyes was remarkably increased by acrylic acid grafting. The light fastness of some basic dyes and a cationic dye, Sumiacryl Red F-GTL on the grafted cotton was good, but that of a cationic dye, Estrol Brilliant Blue N-3RL was poor. Discoloration in laundering was severe in any case. Dyeability for direct and reactive dyes were lower than the untreated cotton fabric. These dyeing characteristics of the acrylic acid grafted cotton fabrics were similar to the carboxymethylated cotton. But in the case of artificial soiling using carbon black dispersion, soiling was higher and soil removal was lower than the untreated cotton fabric, dissimilar to the carboxymethylated cotton.

(Received November 10,1978)

\footnotetext{
前に过らは種々の方法によってつくったカーボキシ メチル化 (以下CM化と略記) 綿布の機械的性質，水分 率(水行少ゲーン)，污染捄よび洗浄性，染色性などの 性質を検討したが、本研究では同じく分子中にカーボキ シル基を導入したアクリル酸グラフト綿布について同様 の此質を測定してCM化綿布におりる結果と比較した。 アクリル酸グラフト綿布については前に过，池由ら は 防しわ性について研究を行ったが，上記のような性質に ついてはまだ研究が行われていない。
}

\section{実験および結果}

試料布としては CM化の場合と同一のユ二チ力製 40 's 平維精練漂白綿布を用いた。

グラフト共重合：アクリル酸水溶液中熱重合拈よび放 射線同時照射法により綿布にアクリル酸グラフトを行っ
た。グラフト率は CM化木綿之対照するために数名〜10 \%を目標とした。熱重合は無触媒で 40〜60\%アクリル 酸水溶液中で $90 \sim 100^{\circ} \mathrm{C}$ 亿加熱して行った。放射線グラ フトは日本原子力研究所大阪研究所においてバンデグう フ加速機（1.5 MeV）在用い電子楾同時照射法に上り行 った。綿布にアクリル酸水溶液古含浸させポリエチレ ン袋に入れて空気在窒菜置換した後，電子線照射を行つ た(Dose rate $\left.0.175 \times 10^{5} \mathrm{rad} / \mathrm{sec}\right) 。$ ホモポリマー の抽出はいずれの場合む $70^{\circ} \mathrm{C}$ 水中 $1 \sim 2 \mathrm{hr}$ 加熱により行 った。

強伸度，水分率，比重：多数のグラフト布について経 系強伸度，水分率，比重虔测定した。若干の例を表 1 に 示す。

熱重合の場合は経糸強力をかなり大きく低下したが， 放射線法では強力低下は僅少であった。水分率は CM化 
Table 1 Properties of acrylic acid grafted cotton fabrics.

\begin{tabular}{ccccccccc}
\hline $\begin{array}{c}\text { Sample } \\
\text { No. }\end{array}$ & $\begin{array}{l}\text { Grafting } \\
\text { method }\end{array}$ & $\begin{array}{c}\text { Acrylic } \\
\text { acid conc. } \\
(\%)\end{array}$ & $\begin{array}{c}\text { Grafting } \\
\text { condition }\end{array}$ & $\begin{array}{c}\text { Grafting } \\
(\%)\end{array}$ & $\begin{array}{c}\text { Warp yarn tensile } \\
\text { Strength \& Elongation } \\
(\mathrm{g})\end{array}$ & $\begin{array}{c}\text { Moisture } \\
\text { regain }) \\
(\%)\end{array}$ & $\begin{array}{c}\text { Specific } \\
\text { gravity }\end{array}$ \\
\hline 1 & Untreated & - & - & 0 & 225 & 8.1 & 6.0 & 1.53 \\
\hline 25 & & & $1.0^{\mathrm{a})}$ & 5.71 & 141 & 6.7 & - & - \\
23 & Heat poly- & \multirow{2}{*}{60} & $1.0^{\mathrm{a})}$ & 5.85 & 137 & 6.1 & 6.2 & 1.54 \\
11 & merization & & $2.5^{\mathrm{a})}$ & 8.96 & 117 & 6.3 & - & - \\
14 & & & $2.5^{\mathrm{a})}$ & 10.69 & 100 & 6.1 & 7.0 & 1.54 \\
\hline 52 & & 5 & $0.25^{\mathrm{b})}$ & 6.00 & 206 & 9.9 & 7.1 & 1.54 \\
51 & Irradi- & 5 & $0.50^{\mathrm{b})}$ & 6.10 & 206 & 8.6 & - & - \\
48 & ation & 10 & $0.50^{\mathrm{b})}$ & 10.30 & 218 & 9.2 & - & - \\
45 & & 20 & $0.50^{\mathrm{b})}$ & 16.10 & 188 & 8.0 & 6.1 & 1.54 \\
\hline
\end{tabular}

a) Time of heat polymerization (hr).

b) Total dose (Mrad).

Table 2 Dyeing property of acrylic acid grafted cotton fabrics for various dyes.

\begin{tabular}{clcccccc}
\hline $\begin{array}{c}\text { Sample } \\
\text { No. }\end{array}$ & $\begin{array}{c}\text { Grafting } \\
\text { method }\end{array}$ & $\begin{array}{c}\text { Crafting } \\
(\%)\end{array}$ & Basic $^{\text {a) }}$ & $\begin{array}{c}\text { Degree } \\
\text { Cationic } \\
(\text { Red })^{\mathrm{b})}\end{array}$ & $\begin{array}{c}\text { of dye exhaustion (\%) } \\
\text { Cationic } \\
(\text { Blue })^{\text {c) }}\end{array}$ & Direct $^{\mathrm{d})}$ & Reactive $^{\mathrm{e})}$ \\
\hline 1 & Untreated & 0 & 7.4 & 20.6 & 9.0 & 13.3 & 17.7 \\
\hline 25 & Heat poly- & 5.71 & 72.0 & 87.4 & 68.7 & 5.3 & 3.3 \\
11 & merization & 8.96 & 74.5 & 83.2 & 75.7 & 6.7 & 2.3 \\
\hline 51 & Irradiation & 6.10 & 77.0 & 73.2 & 47.8 & 8.0 & 7.3 \\
48 & 10.30 & 85.1 & 80.0 & 54.9 & 7.0 & 3.3 \\
\hline \multirow{2}{*}{ Acrylic } & Exlan & - & - & 31.1 & 59.9 & - & - \\
& Cashmilon & - & - & 27.1 & 51.7 & - & - \\
\hline
\end{tabular}

a) Methylene Blue B, b) Sumiacryl Red F-GTL, c) Estrol Brilliant Blue N-3RL,

d) Chrysophenine NS, e) Procion Brilliant Green H-4G.

木綿ほど大きくは增大しない。比重は製処理綿布上ほと んど変りがない。この程度のグラフト率の布は色やかた さが無処理綿布と变らない。

染色性：5種類の染料 (染料名は表 2 脚注に記載) に 上り常法で中色染色を行い，分光光度計に上って染液の 吸光度を測定し次式に上り染着率を求めた。

染着率 $(\not{O})=\frac{C_{1}-C_{2}}{C_{1}} \times 100$

$\left(C_{1}, C_{2}\right.$ はをれぞれ染色前後の染液の染料濃度) 染色方法付次のごをくである。

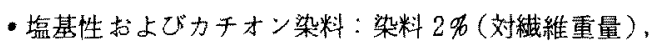
マルセル石けん1\%，酷酸 2 \%。浴比 100 ; 常温で布 をつけ，約 40 分で $90^{\circ} \mathrm{C}$ と，さらに30 分染色。

- 直接染料：染料 $3 \%$ ，無水硫酸ナトリウム $10 \%$ ，無水 炭酸ナトリウム $2 \%$ (いずれあ対織維重量)，非イ才 ン界面活性剂（スコアロール900） $2 \mathrm{~g} / \mathrm{l}$, 浴比 100 ; 染色条件は塩基性染料之同し。

・反応染料：染料 $3 \%$ ，硫酸ナトリウム $40 \mathrm{~g} / l$ ，無水炭 酸ナトリウム $10 \mathrm{~g} / l$, 浴比 100 ; 硫酸ナトリウム含
有染液で常温 30 分染色後, 無水炭酸ナトリウムを添 加, 溶解し, 加温して $90^{\circ} \mathrm{C}$ とし 60 分染色。

染着率の測定結果を表 2 に示す。こ机らの数值は視賞 による判定結果とほぼ一致している。程基性, カチオン 染料では無処理布より染着率は大きく增大する。グラフ ト方法による差違は明確ではない。力チオン染料偟よる 染着率はアクリル瀻維之同様あるいは加なり上回ってい る。直接拈よび反応染料の染着率は無処理布より低い。 これらの各種染料住対する染色性の傾问はCM化竡布と 類似している。

染色堅ろう度：耐光堅ろう度は試料をうエザオメータ 一のカーボンアーク光により(シャワーは用いず)、JIS L 0842 亿準じて露光した。退色の早いものは3，6，9 時間, 堅ろうな子のは $9 ， 18 ， 27$ 時間照射老行い，変 退色用グレースケールに上り退色の程度を判定した。洗 たく堅ろう度は JIS L 0844-A-1 に準じて試験し，第1 添付有之して無処理綿布，第2 添付布として羊毛を用い た。試験結果を 5 段階評価により表 3 亿示す。

グラフト布の耐光堅ろう度は塩基性染料Methylene 
Table 3 Color fastness of acrylic acid grafted cotton fabrics dyed with various dyes.

\begin{tabular}{|c|c|c|c|c|c|c|c|c|}
\hline \multirow{3}{*}{ Dyes } & \multirow{3}{*}{$\begin{array}{l}\text { Sample } \\
\text { No. }\end{array}$} & \multirow{3}{*}{$\begin{array}{l}\text { Grafting } \\
(\%)\end{array}$} & \multicolumn{3}{|c|}{ Light (Carbon-arc Lamp) } & \multicolumn{3}{|c|}{ Laundering } \\
\hline & & & \multirow{2}{*}{$\begin{array}{l}3 \mathrm{~h} \\
(9 \mathrm{~h})\end{array}$} & \multirow{2}{*}{$\begin{array}{c}6 \mathrm{~h} \\
\left.(18 \mathrm{~h})^{\mathrm{d}}\right)\end{array}$} & \multirow{2}{*}{$\begin{array}{c}9 \mathrm{~h} \\
\left.(27 \mathrm{~h})^{\mathrm{d}}\right)\end{array}$} & \multirow{2}{*}{ Change in Color } & \multicolumn{2}{|c|}{ Staining } \\
\hline & & & & & & & Cotton & Wool \\
\hline \multirow{7}{*}{$\begin{array}{l}\text { Basic } \\
\text { (Methylene } \\
\text { Blue B) }\end{array}$} & $1^{a)}$ & 0 & 2 & 1 & 1 & $1-2$ & 5 & 5 \\
\hline & $25^{\mathrm{b})}$ & 5.71 & $3-4$ & 3 & 2 & - & - & - \\
\hline & $20^{\text {b) }}$ & 5.78 & - & - & - & 1 & $2-3$ & 2 \\
\hline & $11^{\text {b) }}$ & 8.96 & 4 & $3-4$ & $2-3$ & - & - & - \\
\hline & $13^{\text {b) }}$ & 8.92 & - & - & - & 1 & 2 & 1 \\
\hline & $51^{c)}$ & 6.10 & 4 & $3-4$ & 3 & 1 & $3-4$ & 3 \\
\hline & $48^{c)}$ & 10.30 & 3 & $2-3$ & 2 & 1 & 2 & $1-2$ \\
\hline \multirow{9}{*}{$\begin{array}{c}\text { Cationic } \\
\text { (Red) } \\
\text { (Sumiacryl } \\
\text { Red F-GTL) }\end{array}$} & 1 & 0 & 5 & $4-5$ & 4 & 3 & 4 & 5 \\
\hline & 25 & 5.71 & $4-5$ & $3-4$ & 3 & - & & - \\
\hline & 20 & 5.78 & - & - & - & 1 & 2 & $2-3$ \\
\hline & 11 & 8.96 & 5 & $4-5$ & 4 & - & & - \\
\hline & 13 & 8.92 & - & - & - & 1 & 2 & 2 \\
\hline & 51 & 6.10 & 5 & 4 & 3 & 1 & 3 & $3-4$ \\
\hline & & 10.30 & $4-5$ & $3-4$ & 3 & $i$ & 3 & 3 \\
\hline & Exlan & - & 5 & 5 & 5 & $4-5$ & $4-5$ & 5 \\
\hline & Cashmilon & - & 5 & 5 & 5 & 4 & 5 & 5 \\
\hline \multirow{9}{*}{$\begin{array}{l}\text { Cationic } \\
\text { (Blue) } \\
\text { (Estrol Brilliant } \\
\text { Blue N-3RL) }\end{array}$} & 1 & 0 & 4 & 3 & 3 & 3 & 5 & 5 \\
\hline & 25 & 5.71 & $2-3$ & 1 & 1 & - & - & - \\
\hline & 20 & 5.78 & - & - & - & 1 & $4-5$ & $4-5$ \\
\hline & 11 & 8.96 & 3 & $1-2$ & 1 & - & - & - \\
\hline & 13 & 8.92 & - & - & - & 1 & 4 & $3-4$ \\
\hline & 51 & 6.10 & 2 & 1 & 1 & 1 & $4-5$ & 5 \\
\hline & 48 & 10.30 & 2 & 1 & 1 & 1 & 4 & 4 \\
\hline & Exlan & - & 5 & 5 & 5 & 5 & 5 & 5 \\
\hline & Cashmilon & - & 5 & 5 & 5 & 5 & 5 & 5 \\
\hline \multirow{7}{*}{$\begin{array}{l}\text { Direct } \\
\text { (Chrysophenine } \\
\text { NS) }\end{array}$} & 1 & 0 & $(5)^{d)}$ & $(5)^{d)}$ & $(5)^{d)}$ & 3 & 3 & 5 \\
\hline & 25 & 5.71 & (5) & (5) & (4) & - & - & - \\
\hline & 20 & 5.78 & - & - & - & 3 & 4 & 5 \\
\hline & 11 & 8.96 & $(3-4)$ & $(3-4)$ & (3) & - & - & - \\
\hline & 13 & 8.92 & - & - & - & $3-4$ & 4 & 5 \\
\hline & 51 & 6.10 & (5) & (5) & (4) & $3-4$ & $3-4$ & 5 \\
\hline & 48 & 10.30 & $(4-5)$ & (4) & $(3-4)$ & 4 & 4 & 5 \\
\hline \multirow{7}{*}{$\begin{array}{l}\text { Reactive } \\
\text { (Procion Brilliant } \\
\text { Green } H-4 G \text { ) }\end{array}$} & 1 & 0 & $(5)^{d)}$ & $(4)^{d)}$ & $(3-4)^{d)}$ & $3-4$ & $4-5$ & $4-5$ \\
\hline & & 5.71 & (5) & $(4-5)$ & (4) & - & - & - \\
\hline & 20 & 5.78 & - & $\ldots$ & - & 4 & $4-5$ & 5 \\
\hline & 11 & 8.96 & (4) & (3) & (2) & - & - & - \\
\hline & 13 & 8.92 & - & - & - & 3 & $4-5$ & 5 \\
\hline & 51 & 6.10 & $(4-5)$ & $(3-4)$ & (3) & $3-4$ & $4-5$ & 5 \\
\hline & 48 & 10.30 & $(4-5)$ & (4) & $(3-4)$ & 4 & $4-5$ & 5 \\
\hline
\end{tabular}

a) Untreated cotton fabric.

b) Grafted by heat polymerization.

c) Grafted by irradiation.

d) Values of light fastness in parenthesis for the direct and reactive dyes show the values obtained at the time of exposure of 9,18 and 27 hours, respectively.

- Colorfastness to carbon-arc lamp was evaluated by comparing the degree of fading with the gray scale for evaluating change in color and classified in $1-5$ classes.

Blue Bではさして覀くなく，CM化綿布とほぼ同じで ある。カチオン染料では Sumiacryl Red F-GTLはア クリル啭維に近い良結果を示したが，Estrol Brilliant Blue N-3RLではCM化綿布の場合と同しく著しく低
い值を示した。洗たく堅ろう度は塩基性，カチオン染料 のいずれも変退色が大きく，CM化綿布の場合同様の問 題点を残す。直接，反応染料では光，珗たくともに堅ろ う度の值は悪くないか，とれらは前述のように染着性か 
無爸理綿布より低い。

污染および洙浄性：过らは前にモノクロル酢酸あるい

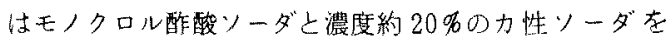
用いて2浴法で作整したCM化綿有が無观理綿在よりや

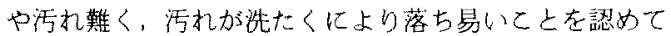
いる ${ }^{1,3)}$ 。また本研究施行中に発表されたMaresら”研 究に上れで，窒素中コバルト60r線前照射法に上りメ夕 クリル酸をグラフトした線布が，カーボンブラックの水

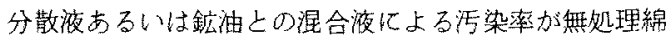
布上り小さく，洗浄効率が大さいととが認められた。了 クリル酸グラフト綿布に执いても同様な効果が期街され Z。

RH65\%で調湿したアクリル酸グラフト綿有を力ーボ ンブラックの四塩化炭㨞分散液に1 分漫漬風乾した。こ れをRH55\%デシケーター中に14日放置後，ラウンダ オメ一多一虫 $0.3 \%$ マルセル石け九水溶液で $40^{\circ} \mathrm{C} ４ 40$ Ipmで 30 分洗净した。分光光度計で波長 $550 \mathrm{~m} \mu$ で布 の反射率を测定し，次式に上り活染率扰上び洗津効率を 算出した。
活染率 $(\%)=\frac{R_{0}-R_{\mathrm{S}}}{R_{0}} \times 100$

洗浄效率 $(\%)=\frac{R_{\mathrm{W}}-R_{\mathrm{S}}}{R_{0}-R_{\mathrm{S}}} \times 100$

$\left(R_{0} ， R_{\mathrm{S}} ， R_{\mathrm{w}}\right.$ はそれぞれ原白布，活染布，洗净有 の反射率)

得られた結果老表 4 亿示す。予期に反してグラフト布 の污染率は無処理布上りやや大きく，洗浄效率当大きい とはいえない。そこで前記Maresら゙のメタクリル酸グ ラフト綿有の実験結果がグラフト率 15〜22\%の試料儿 いて得られだのであることも考慮して，グラフト率 のより高い $(20.8 ， 22.5 \%$ ，電子線照射法）詿料布につ いて同漛の実験を行った。参考のためにグラフト布を炭 酸ナトリウム 5 \% 水溶液に 60 Cで 1 時間浸清してNa塩 の形に変えた試料についても実験を行ったが，結果は表 5 に示すようにいずれの場合すグラフト布の方が無题理 有より污染率が大きく，洗鿇効率が小さい結果となった。 これらの傾向は㬰験布の肉眼観察によって古認められた さらに分散剤（花王エマルゲン909）を使用してカー

Table 4 Property of acrylic acid grafted cotton fabrics for soiling and washing (I).

\begin{tabular}{ccccc}
$\begin{array}{c}\text { Sample } \\
\text { No. }\end{array}$ & $\begin{array}{c}\text { Grafting } \\
\text { method }\end{array}$ & $\begin{array}{c}\text { Grafting } \\
(\mathscr{\%})\end{array}$ & $\begin{array}{c}\text { Soiling } \\
(\%)\end{array}$ & $\begin{array}{c}\text { Soil removal } \\
(\%)\end{array}$ \\
\hline 1 & Untreated & 0 & 61.4 & 27.5 \\
\hline 20 & Heat poly- & 5.78 & 65.1 & 22.1 \\
14 & merization & 10.69 & 68.0 & 28.5 \\
\hline 52 & Irradiation & 6.00 & 62.8 & 26.7 \\
47 & 12.00 & 66.4 & 19.5 \\
\hline
\end{tabular}

a) Carbon black $0.02 \mathrm{~g}$, carbon tetrachloride $80 \mathrm{~g}$, beef tallow $0.1 \mathrm{~g}$, liquid paraffin $0.3 \mathrm{~g}$.

Table 5 Property of acrylic acid grafted cotton fabrics for soiling and washing (II).

\begin{tabular}{|c|c|c|c|c|c|}
\hline $\begin{array}{c}\text { Sample } \\
\text { No. }\end{array}$ & $\begin{array}{c}\text { Grafting } \\
(\%)\end{array}$ & $\begin{array}{c}\text { Sample } \\
\text { type }\end{array}$ & $\begin{array}{l}\text { Solling } \\
\text { Iiquor }\end{array}$ & $\begin{array}{l}\text { Soiling } \\
(\%)\end{array}$ & $\begin{array}{c}\text { Soil removal } \\
(\%)\end{array}$ \\
\hline $\begin{array}{r}1 \\
44 \\
42 \\
\end{array}$ & $\begin{array}{c}0 \\
20.8 \\
22.5 \\
\end{array}$ & \multirow{2}{*}{$\mathrm{AA}^{\mathrm{b})}$} & d) & $\begin{array}{l}53.2 \\
61.4 \\
61.2\end{array}$ & $\begin{array}{l}45.2 \\
17.5 \\
18.3\end{array}$ \\
\hline $\begin{array}{r}1 \\
44 \\
42\end{array}$ & $\begin{array}{c}0 \\
20.8 \\
22.5\end{array}$ & & e) & $\begin{array}{l}72.5 \\
73.3 \\
74.0\end{array}$ & $\begin{array}{l}31.6 \\
21.5 \\
19.5\end{array}$ \\
\hline $\begin{array}{r}1 \\
44\end{array}$ & $\begin{array}{c}0 \\
20.8\end{array}$ & $\mathrm{AA}-\mathrm{Na}^{\mathrm{c})}$ & e) & $\begin{array}{l}72.2 \\
83.2\end{array}$ & $\begin{array}{l}25.6 \\
23.4\end{array}$ \\
\hline
\end{tabular}

a) Grafted by irradiation.

b) Acrylic acid grafted.

c) Acrylic acid grafted and Na-substituted by $\mathrm{Na}_{2} \mathrm{CO}_{3}$ treatment.

d) Carbon black $0.02 \mathrm{~g}$, carbon tetrachloride $80 \mathrm{~g}$, beef tallow $0.1 \mathrm{~g}$, liquid paraffin $0.3 \mathrm{~g}$.

e) Carbon black $0.1 \mathrm{~g}$, carbon tetrachloride $80 \mathrm{~g}$, beef tallow $0.1 \mathrm{~g}$, liquid paraffin $0.3 \mathrm{~g}$. 
Table 6 Soiling of acrylic acid grafted cotton fabrics for aqueous soil.

\begin{tabular}{rcccc}
\hline $\begin{array}{c}\text { Sample } \\
\text { No. }\end{array}$ & $\begin{array}{c}\text { Grafting } \\
(\not)\end{array}$ & $\begin{array}{c}\text { Soiling } \\
\text { liquor }\end{array}$ & $\begin{array}{c}\text { Soiling } \\
(\not)\end{array}$ & $\begin{array}{c}\text { Soil removal } \\
(\%)\end{array}$ \\
\hline 1 & 0 & a) & 37.5 & 40.9 \\
44 & 20.8 & & 50.9 & 39.3 \\
\hline 1 & 0 & b) & 44.5 & 32.8 \\
44 & 20.8 & b) & 59.6 & 28.1 \\
\hline
\end{tabular}

a) Carbon black $0.05 \mathrm{~g}$, dispersing agent $0.4 \mathrm{~g}$, water $80 \mathrm{cc}$.

b) Carbon black $0.1 \mathrm{~g}$, dispersing agent $0.4 \mathrm{~g}$, water $80 \mathrm{cc}$.

ボンブラックを蒸留水中に分散した污染液を用いて同様 の実験索行った。結果は表 6 亿示すように，四塩化炭素 分散污染波心場合上同梾な項向が認奻らた。

以上のようにアクリル酸グラフト綿布の活染および洗 净性については，CM化およびメタクリル酸グラフト綿 布とは異なる結果を得たが，こ扎てついてはな书今後の 揄討を要豆る。

本研究についてで協力在得た日本原子力研究所大阪研 究所ならび実験材料を供与されたユニチ力，住友化学 工業仙感謝の意を表する。

なお本研究の大部分は綞維学会年次大会 (昭和 52 年 6 月、東京)に扔いて発表しだ〉。
文献

1) 辻和一郎，後竹葉子，畑 直美，中尾時枝；瀻学 誌, 33, T-133 (1977)

2）池田徹雄, 池田洋子，伊藤澄子，辻 和一郎；瀻学 誌, $\mathbf{3 0}, \mathrm{T}-292(1974)$

3）过和一郎は加; 日本綿業技術研究所研究報告, No. 14（1956）：No.49（1961）；京大化瀻研講演集， 16, 121(1959)

4) T. Mares, J. C. Arthur and J. A. Harris; Text. Res. J., 46, 563 (1976)

5）辻 和一郎, 池田房代, 長谷川智三, 中尾時枝; 繊 維学会昭和 52 年度年次大会講演要旨集， p. 267 (1977) 